\title{
On the impact of COVID-19 pandemic on the intention to leave the parental home
}

\author{
Francesca Luppi ${ }^{1}$, Alessandro Rosina ${ }^{1}$, Emiliano Sironi ${ }^{1}$ \\ ${ }^{1}$ Deparment of Statistics, Università Cattolica del Sacro Cuore, Largo Gemelli 1, 20123 Milan (Italy)
}

\begin{abstract}
With the spread of the SARS-CoV-2 pandemic all over Europe during the first months of 2020, most of the European governments imposed restrictive measures to people mobility and physical distance (the lockdown), which severely impacted on the economic activities and performance of many countries. Thus, the health emergency turned rapidly into in an economic crisis. The Covid-19 crisis in Europe increased the uncertainty about the economic recovery and the end of the health emergency. This situation is supposed to have conditioned individuals' life course path with the effect of inducing people to postpone or to abandon many life plans.

This paper aims to explore whether the rise of health emergency due to the Covid-19 has delayed or vanished young people intention to leave the parental home during the 2020 in five European countries: Italy, Germany, France, Spain and UK. Using data from an international survey from the "Youth Project", carried out by the Toniolo Institute of Advanced Studies, this paper implements ordered logistic models in order to investigate the determinants of a possible revision of the choice of leaving the parental home for a representative sample of 6,000 respondents aged 18 to 34, interviewed between March and April 2020. A special focus has been pointed on the Italian case, because of being the first European country to be strongly hit by the pandemic and because of the already economic vulnerable conditions of its young population.

Results reports that Italy is the country with the highest rate of downward revisions of the intentions of leaving the nest. In particular, having negative expectations about changes in the individual's and family's future income is a key predictor of the choice of abandoning the purpose of leaving the parental home across Europe. However, the vulnerability of the category of temporary workers arises especially in Italy: young people with precarious jobs seems to be the most prone to negatively revise their intentions of leaving, even compared with those not working.
\end{abstract}

Keywords: Covid-19, SARS-CoV2, Coronavirus Leaving parental home, Intentions, Young people 


\section{Introduction}

Economic recessions tend to prolong the time needed for young people to make their transition to adulthood. The 2008 Great Recession has largely shown the mechanisms at work: because economic crises especially reduce youth employment opportunities (Bell and Blanchflower 2011; Schoon and Bynner 2017), the pre-existing tendency towards prolonged education participation and precarious occupations has been accentuated. This process resulted, for many young people, into a postponement of some life events such as reaching housing and economic independence from the family of origin. These effects have been especially evident among Southern European countries, and particularly in Italy (Sironi 2018), where the effect of the economic recession summed up with an unfavourable labour market situation, scarce welfare state provisions and a struggling economic system. In this context of less-protective transition regimes (i.e. from youth to adulthood), the result has been a strong increase of the youth unemployment rate, the spread of involuntary temporary occupations and the enlargement of the subgroup of young individuals neither in employment nor in education or training (NEET) (e.g. Schoon and Bynner 2019). All these conditions have been found related with a lower propensity to undertake the traditional steps toward the transition to adulthood (Rosina et al. 2007, Sironi and Rosina 2015, Vignoli et al. 2012, Vignoli et al. 2013, Vignoli et al. 2016).

The Covid-19 health crisis, which picked in Europe with the lockdown restrictions implemented in most of the European countries between February and March 2020, had suddenly translated into a severe global economic crisis. Because of the previous considerations, even though we cannot assimilate the Covid-19 related economic turndown with the 2008 Great Recession, we can expect that this economic crisis will strongly hit - again - the young population, threatening their life plans. In particular, the decision to exit the parental home especially requires reaching some economic independence, which can be easily compromised during an economic recession period.

The aim of the present study is to explore the variation in the intention of leaving the parental home as a consequence of the Covid-19 crisis, among a set of five European countries (i.e. Italy, France, 
Germany, Spain and UK). In particular, we investigate whether previous individual's occupational condition and the expected effect of the crisis on the individual's and family's income impact on the decision of withdrawing or postponing the plan of acquiring a housing independence. Further, we specifically focus on the Italian case: leaving the nest usually happens later in Italy than in other Western European countries, the effect of the economic uncertainty generated by the current crisis might even exacerbate this phenomenon. Additionally, in our sample, Italy is the country where the economic conditions, the labour market structure and the type of welfare regime create a particular unfriendly environment for young people to get their economic independence and security. The analyses have been conducted on data coming from an international survey on representative samples of the young population (18-34) of the five European countries. The interviews have been conducted between March 27 and April 7 2020, when the lockdown restrictions had been already adopted in most of the considered countries.

\section{Background}

Leaving the parental home is one of the first steps in the transition to adulthood. This typically happens for reasons such as studying in another city/country, because the individual reaches an economic independence from the family of origin, or because of starting a cohabitation with a partner (Billari, Philipov, and Baizán 2001; De Jong Gierveld, Liefbroer, and Beekink 1991). Historically, the age of leaving the family of origin has grown over time, particularly since the late Sixties of the last Century, due to the institutional and values changes that took place in Western societies in that period (Aassve et al. 2002; Furstenberg 2010; Settersten et al. 2008; Sironi and Furstenberg 2012, Lesthaeghe and Van de Kaa 1986). The increased family investment in children, the prolonged time spent by children in the education system, the desire of finding a job that matches their qualification, and, last but not least, the increased well-being of the families of origin are among the factors that have contributed to postpone the "right" time of leaving the parental home (Buchmann and Kriesi 
2011; Sironi 2015). Almost unavoidable it is the prerequisite of having acquired the economic selfsufficiency or getting access to the financial support of the family of origin or of a partner (Goldscheider and Goldscheider 1993; Aassve et al. 2002; Iacovou 2010). On the contrary, young people tend to stay longer in the parental home if leaving would increase their poverty risk (Aassve et al. 2007).

Consequently, the kind of job young people get access when entering the labour market contributes to determine the chance of gaining financial and housing independence from the family of origin. As a result of the globalization process, the structure of the labour market has changed dramatically since the last 30 years, by increasing occupational uncertainty at every stage of the work career, but especially for those entering the labour market for the first time (Mills and Blossfeld 2003). Young people, in fact, usually experience greater difficulties in getting a job and higher instability of their positions and contracts if compared to those with longer working histories (Blanchflower and Freeman 2000; Breen 2005; Brzinsky-Fay 2007; Gangl 2002; Scherer 2005).

The intention of staying or leaving the family of origin may depend also on macro-level socioeconomic and cultural factors. Several studies have stressed the role of contextual variables such as the structure of the labour market, the dominant values system and the type of welfare state.

The labour market condition has a strong power in explaining the different timing of leaving the parental home across countries (Aassve et al., 2002, 2010), because having a stable job and/or experiencing low risk of unemployment is a precondition for reaching a financial autonomy. On the contrary, a context where young people are at high risk of unemployment discourages from leaving the parental home. This mechanism at least partially explains the lower propensity of young Italians to make this step towards the adulthood: Italy, in fact, is the European countries with the highest proportion of NEET - i.e. young people nor Employed neither in Education or Training - (in 2019, among those aged 15 to 34 , the percentage of NEETs in Italy was 23.8 while the EU28 average was 13.6. Source: Eurostat). Their incidence has especially risen as effect of the 2008 Great Recession, 
which increased youth unemployment through hitting temporary contracts, largely widespread among young, low-skilled workers (Lin et al. 2013, Sironi and Rosina 2015).

Welfare policies can act positively in reducing the uncertainty due to unfavourable conditions of the labour market, and thus supporting young people in their transition towards financial autonomy. It has been widely shown in the literature that the type of welfare state is linked to different timing and paths to adulthood (Buchmannand Kriesi 2011, Sironi 2015), with the most generous welfare systems effectively promoting the process of leaving the parental home. By referring to the Esping-Andersen typology (Esping- Andersen 1990), in the cluster of Southern Europeans countries the transition to adulthood happens later in life if compared to countries characterized by other types of welfare regimes (Aassve et al. 2002, 2006; Aassve and Lappegård 2009; Billari 2004; Billari et al. 2001; Esping-Andersen 1990; Mills et al. 2008; Mulder et al. 2002). In this cluster of countries, and in the Italian case in particular, the welfare system is not particularly generous towards young people (Rosina et al., 2007, Barbieri 2011). Therefore, usually the low provision of support provided by the welfare state is balanced by the family support network (Mayer 2001; Trifiletti 1999). Consequently, young people in familialistic countries tend to minimize their income risk by relying on family support and postponing the leaving from the parental home (Blossfeld et al. 2005). Obviously, this is conditional to the economic and social situation of the family of origin, and in particular its possibility to financially support child's decision of reaching a housing independency (De Long Gierveld; Liefbroer and Beekink 1991, Santarelli and Cotone 2009).

The institutional setting conditions the transition to adulthood also through the values system, which is implicit in the everyday social interactions, especially in the family context. Parental attitudes and value orientation (Goldscheider and Goldscheider 1989; Surkyn and Lastehaeghe 2004) guide the evaluation of the preconditions and the timing for leaving the parental home. Cultural differences are wide across countries. In Italy, as in the Southern European countries, the family relationships, and in particular those between parents and children, are especially solid, because they often are the 
primary source of emotional and material support for young adults (Dalla Zuanna 2001, Dalla Zuanna and Micheli 2004). As already said, this special type of intra-family relationship derives also by the institutional setting - and the type of welfare state in particular - whose inefficiency in supporting young people economic independence is often compensated by the support provided by the family network.

The economic cycle phase also matters; recessions, in fact, have the power to increase the difficulties in making the transition to adulthood. This happens because young people are extremely financially vulnerable to economic crises (Aassve et al. 2013, Bell et al. 2011; Cho and Newhouse 2013, Sironi 2018; Grusky et al. 2011; Hout et al. 2011; Mínguez et al. 2017; O’Higgins 2014; Verick 2009). Those working before the crisis are usually employed in sectors that are particularly affected by recessions (O’Higgins 2014; Verick 2009). Additionally, because employed young people are at the beginning of their work career, they usually rely on informal or temporary contracts, which are easily at risk of ending during these problematic periods (Marcus and Gavrilovic 2010). Finally, those who did not enter the labour market yet face increased difficulties in finding a job, while if they finally succeed to get an occupation it is usually very precarious (Sironi 2018). Because recessions undermine the occupational stability and the prospect and real earnings of young people (Sironi 2018), which are prerequisites for gaining a financial and housing autonomy, most of them postpone the steps towards the transition to adult during economic crises (Aassve et al. 2002, Bell et al. 2007, Iacovu 2010, Fustenberg 2010). However, recessions do not hit the young population uniformly. Differences in the impact of recessions on the young population may depend on the type of welfare regime and values system. More protective and generous welfare regimes towards young generations (e.g. sustaining the transition from education to labour market, providing income and housing support, etc.) tend to reduce the economic uncertainty and vulnerability derived by the economic crises (Schoon and Bynner 2019). In less protective welfare regimes, such as in Southern Europe, given the occupational and income instability due to the recession, young people may decide simply to prolong 
their stay in the parental home to avoiding any additional income risks derived by the crisis (Sironi 2018).

\section{Data, methods and variables}

Data used in this study come from the "Youth Project", a survey started in 2011 within the financial support and the partnership of the Toniolo Institute of Advanced Studies and CARIPLO Foundation and with IPSOS LTD as executive and technical partner. In 2020, an international survey promoted within the "Youth Project", focuses on the consequences of the Covid-19 pandemic on the life course plans of a representative sample of the population of European young adults (people aged 18 to 34). A sample of 6,000 European young adults participated in the research. Among them 2,000 come from Italy and 1,000 come from each of the following European countries: UK, Germany, France, Spain. The interviews have been conducted between March 27-31, 2020 in Italy and April 2-7, 2020 in the other countries. The survey was realized using quotas sampling: quotas (defined using variables such as gender, age, geographical origin, education, marital status, etc.) are designed to reflect the population and are representative of the country's population after having corrected frequencies through a weighting procedure. The interviews were carried using CAWI method (Computer Aided Web Interviewing: the questionnaire is online available; the interviewee opens the webpage and automatically answers the questions that appear on the screen. More technical details are available at https://www.rapportogiovani.it/osservatorio/).

Descriptive statistics about the socio-demographics characteristics of the interviewed individuals are reported in Table 1.

Table 1: Descriptive statistics of the total sample distribution.

\begin{tabular}{lccccc}
\hline & Italy & UK & Germany & France & Spain \\
\hline \hline Gender & & & & & \\
\hline Male & $51.0 \%$ & $50.6 \%$ & $52.1 \%$ & $49.6 \%$ & $50.4 \%$ \\
Female & $49.0 \%$ & $49.4 \%$ & $47.9 \%$ & $50.4 \%$ & $49.6 \%$ \\
\hline
\end{tabular}




\begin{tabular}{lccccc}
\hline Age (in years) & & & & \\
\hline $18-24$ & $31.9 \%$ & $31.2 \%$ & $30.3 \%$ & $32.7 \%$ & $30.2 \%$ \\
$25-29$ & $31.8 \%$ & $34.4 \%$ & $34.2 \%$ & $32.3 \%$ & $32.1 \%$ \\
$30-34$ & $36.3 \%$ & $34.4 \%$ & $35.5 \%$ & $35.0 \%$ & $37.7 \%$ \\
\hline Residential status & & & & \\
\hline Already left parental home & $51.1 \%$ & $70.6 \%$ & $76.5 \%$ & $74.0 \%$ & $56.0 \%$ \\
Never left parental home & $48.9 \%$ & $29.4 \%$ & $23.5 \%$ & $26.0 \%$ & $44.0 \%$ \\
\hline Observations & 2000 & 1000 & 1000 & 1000 & 1000 \\
\hline Source: Youth project, International survey $(2020)$ & & & &
\end{tabular}

Source: Youth project, International survey (2020)

The 2020 international survey includes a set of items exploring European young adults' perspectives on their life plans for the same year (e.g. leaving the parental home, conceiving a child, getting married, started a cohabitation with the partner, moving to another country, changing the current job). This paper focuses on the decision of European young adults to leave the parental home during 2020 and on how they reconsidered the plan in light of the effects of the Covid-19 pandemic. Hence, the sample explored in the data analysis is restricted to the subset of individuals who live with their family of origin at the time of the interview (March/April 2020) and who were considering going to live on their own at the beginning of the year (January 2020).

As shown in Table 1, different patterns of living arrangements characterized the five sampled countries. With respect to the residential condition, in Italy the percentage of young adults who still live within the family origin at the time of the interview is greater than in the other countries (48.9\%), but similar to the Spanish case (44\%). This result confirms the Southern European habit of leaving the nest later, at least if compared with the other countries considered in this study: in Germany, France and U.K, in fact, the percentage of individuals living with the parents is less than $30 \%$ in our sample. This gap in the proportion of those who have already achieved housing self-sufficiency across countries has been linked in the literature to the different occupational vulnerability experienced by the young workforce. The material deprivation, due to higher youth unemployment and precarious jobs rates, has been recognized as one of the main reasons for the delay in leaving the parental home. 
Table 2 shows the proportion of individuals in the sample who were considering going to live on their own before the beginning of Covid-19 emergency. As we can see from the table, the percentage of individuals intentioned to leave the parental home before the beginning of the pandemic is lower than the percentage of those who were intentioned. Only apparently surprising is the results of Italy, who displays the highest rate of people intentioned to leave the nest. The result is related to what we have discussed in Table 1: Italy is the country with the higher proportion of individuals still living with their parents (and having postponed in the past years); consequently, we observe also the highest potential of individuals who aim at joining the residential autonomy.

Table 2: People that were considering going to live on their own in January 2020.

\begin{tabular}{lccccc}
\hline & Italy & UK & Germany & France & Spain \\
\hline \hline $\begin{array}{l}\text { People who were considering it } \\
\text { but had not made a plan }\end{array}$ & $22.5 \%$ & $14.6 \%$ & $20.6 \%$ & $16.9 \%$ & $15.9 \%$ \\
People who were planning on it & $13.1 \%$ & $11.6 \%$ & $6.1 \%$ & $15.9 \%$ & $11.2 \%$ \\
\hline Observations & 2000 & 1000 & 1000 & 1000 & 1000 \\
\hline
\end{tabular}

Source: Youth project, International survey (2020)

The result in Table 3 focuses on the central point of this study, which is the decision to confirm or to revise the intention of leaving the parental home, considering the crisis due to Covid-19 pandemic: the analysed subsample is focused on the individuals that reported a positive intention of leaving the parental home in January 2020. The Covid-19 emergency has had a strong impact in depressing the purposes of the interviewed individuals: in all the European countries the percentage of those who postponed or abandoned the plan of leaving the parental home exceed sharply the percentage of those who confirm their plan.

Although the pandemic has a generalized impact of delaying or denying the choice of young adults of going to live on their own, some specificities at the country level arise. In particular, Italy performs 
worse with regard to the other countries, showing the highest proportion of young adults who revised the intention of exiting from the parental home: $45.6 \%$ of the respondents decided to postpone their plans, while $34.7 \%$ of them totally abandoned the idea. Coherently with the expectations, in this framework, Spain is the runner up in the ranking of intentions revised: $29.2 \%$ of respondents renounce to going to live on their own.

Nevertheless, the economic instability and the sense of uncertainty due to the spread of Covid-19 also hit the young people plans in countries like Germany and UK. In France, the effect of the pandemic seems to be milder, even if the higher fraction of those who declare of postponing the plan counterbalance those who renounce to their purpose.

Table 3. People that were reconsidering going to live on their own in light of Covid-19 pandemic (answers conditioned on positive answers to the item in Table 2).

\begin{tabular}{lccccc}
\hline & Italy & UK & Germany & France & Spain \\
\hline $\begin{array}{l}\text { People who confirm the plan, } \\
\text { despite Covid-19 pandemic }\end{array}$ & $19.7 \%$ & $25.1 \%$ & $30.6 \%$ & $31.7 \%$ & $19.4 \%$ \\
$\begin{array}{l}\text { People who declared that plan is } \\
\text { still happening, but it was } \\
\text { postponed }\end{array}$ & $45.6 \%$ & $50.7 \%$ & $46.4 \%$ & $55.3 \%$ & $51.4 \%$ \\
$\begin{array}{l}\text { People who abandoned that plan } \\
\text { Observations }\end{array}$ & $34.7 \%$ & $24.2 \%$ & $23.0 \%$ & $13.0 \%$ & $29.2 \%$ \\
\hline
\end{tabular}

Source: Youth project, International survey (2020)

The paper aims at testing the role played by socio-demographic characteristics and by the perception of future economic conditions deriving from the Covid-19 emergency on the individuals' decision to confirm or not the purpose of going to live on their own.

Hence, the dependent variable of the model is the one presented in Table 3, with three possible levels of responses $j$ hierarchically ordered from the most optimistic point of view related to the intentions of leaving the parental home $(j=1)$ to the less optimistic one $(j=3)$, which overlaps with the choice of 
a complete renounce to the intention of leaving the nest. In more detail the following is the pool of available levels for variable $j$ :

- Confirmation of the plan [of going to live outside the family of origin] - $(j=1)$

- Postponement of the plan [that is formally confirmed, but delayed for what concerning the date of departure] - $(j=2)$;

- Abandonment (suspended sine die) of the plan to reach residential autonomy. Two different model specifications are used in order to model the responses of the outcome variable $-(j=3)$.

Two different model specifications are then presented: (1) the model assuming ordinality of the outcomes and the parallel line assumption. This model is also well-known as an ordered logistic model; (2) a more flexible model which provides unbiased and consistent estimates even if the parallel line assumption does not hold, which is well knows in literature as the generalized logistics regression (Williams, 2016).

1) Let $Y_{i}$ be the outcome for the individual $i$ : under the ordinality assumption of the response outcome in three different levels (each of them is equal to $j$, with $j=1,2,3$ ), the model assumes the following form:

$$
\begin{gathered}
\operatorname{Pr}\left(Y_{i} \leq j \mid X_{i}\right)=F\left(X_{i} \beta\right)=\frac{1}{1+\exp \left(\alpha_{j}+X_{i} \beta\right)}=1-\frac{\exp \left(\alpha_{j}+X_{i} \beta\right)}{1+\exp \left(\alpha_{j}+X_{i} \beta\right)} \\
\operatorname{Pr}\left(Y_{i}>j \mid X_{i}\right)=1-F\left(X_{i} \beta\right)=\frac{\exp \left(\alpha_{j}+X_{i} \beta\right)}{1+\exp \left(\alpha_{j}+X_{i} \beta\right)} \\
\text { with } j=1,2,3
\end{gathered}
$$

Where the $X_{i}$ is the set of regressors for the respondent $i$ and $\beta$ are the coefficients of the independent variables to estimate. The model specified above is the correct one if the parallel line assumption holds. The parallel line assumption states that parameters $\beta$ should not change 
for different categories $j$. If it does not happen, then the size of the coefficients of some explanatory variables depends on the cut-off points of the dependent variable.

A Brant test (Brant, 1990) has been implemented, in order to verify whether the parallel line assumption holds or not, showing that in every model for at least one variable parallel line is violated $^{1}$.

2) With respect to those coefficients that do not pass the Brant test and for which the parallel line assumption condition does not hold, generalized logistic regression estimates are used in order to replace the ordered logistic ones. In more detail, this model allows to perform different strategies to treat variables that fail the parallel line assumptions and those not violating that condition. More specifically, if the parallel line assumption holds, the coefficient estimates are the same as from an ordered logistic model. If the parallel line assumption fails, a series of cumulative logit models have been run: the original ordinal variable is collapsed into two categories and a series of binary logistic regressions are estimated. First, it is category 1 (confirmation) versus categories 2 and 3 (postponement or abandonment); then it is category 1 and 2 (confirmation or postponement) versus category 3 (abandonment); the model, as in Williams (2016) assumes the following specification:

$$
\operatorname{Pr}\left(Y_{i}>j \mid X_{i}\right)=1-F\left(X_{i} \beta_{j}\right)=\frac{\exp \left(\alpha_{j}+X_{i} \beta_{j}\right)}{1+\exp \left(\alpha_{j}+X_{i} \beta_{j}\right)}
$$

As we can see we relax in this case the hypothesis that coefficients $\beta$ are constant for every level $j$ of the dependent variable. If we consider a generic level $j$ and we require the probability of joining the threshold $j$, we obtain:

$$
\operatorname{Pr}\left(Y_{i}=j \mid X_{i}\right)=\frac{\exp \left(\alpha_{j-1}+X_{i} \beta_{j-1}\right)}{1+\exp \left(\alpha_{j-1}+X_{i} \beta_{j-1}\right)}-\frac{\exp \left(\alpha_{j}+X_{i} \beta_{j}\right)}{1+\exp \left(\alpha_{j}+X_{i} \beta_{j}\right)}
$$

\footnotetext{
${ }^{1}$ This result mentioned in the text is omitted from the tables of simple ordered regressions.
} 
Replacing $j$ with the numeric levels 1, 2 and 3 we will have that:

$$
\begin{gathered}
\operatorname{Pr}\left(Y_{i}=1 \mid X_{i}\right)=1-\frac{\exp \left(\alpha_{j}+X_{i} \beta_{1}\right)}{1+\exp \left(\alpha_{j}+X_{i} \beta_{1}\right)} \\
\operatorname{Pr}\left(Y_{i}=2 \mid X_{i}\right)=\frac{\exp \left(\alpha_{1}+X_{i} \beta_{1}\right)}{1+\exp \left(\alpha_{1}+X_{i} \beta_{j-1}\right)}-\frac{\exp \left(\alpha_{2}+X_{i} \beta_{2}\right)}{1+\exp \left(\alpha_{2}+X_{i} \beta_{2}\right)} \\
\operatorname{Pr}\left(Y_{i}=3 \mid X_{i}\right)=\frac{\exp \left(\alpha_{2}+X_{i} \beta_{2}\right)}{1+\exp \left(\alpha_{2}+X_{i} \beta_{2}\right)}
\end{gathered}
$$

In both the cases estimates of parameters $\beta$ are obtained using a Maximum Likelihood Estimation. Procedure.

The vector of variables $X_{i}$, which is used in the empirical analysis includes the following predictors: Gender: by distinguishing among males and females, we take into account that the trajectories characterizing the transition to adulthood may differ by gender.

Age: we grouped the individuals in three age classes: 18-24, 25-29 (reference category) and 30-34.

Education: we distinguish young adults who achieved a tertiary level of education (bachelor, master or $\mathrm{Ph}$. D) from those that achieved an upper secondary education (with a 4 or 5 years high school diploma) and from a residual group including those that have lower levels of education (lower secondary or primary).

Geographical area: it is an explanatory variable introduced, in order to take into account the geographical heterogeneity and the impact of unobservable context variables. In the European context we consider the five biggest countries in terms of population size: Italy (which is the reference category), Germany, France; UK and Spain. In the subsequent analysis which focuses only on the Italian context country dummies are replaced with macroregional dummies (NUTS 1 level): Northwest (reference), Northeast, Centre, South and Islands.

Employment status: a key variable which is strongly related with the available economic resources. We consider five categories: students, NEETs, temporary workers (employees with a fixed term job), 
permanent employees (employees without a contract expiration date) and self-employed (a category including young entrepreneurs and freelancers, which has been chosen as the reference category). Perceived future income and job conditions: it is a variable which explores respondents' expectation about their future job and the future income of their family. The question used for building the variable collects the answers to the following question: "Looking to the future, do you think the current coronavirus emergency will have a positive or negative impact? a) on your family's income b) on your job. For each item five alternatives answers have been provided in the questionnaire: 1) Very negative, 2) Somewhat negative, 3) No change, 4) Somewhat positive, 5) Very positive.

Starting from the five possible answers for the two explored items we create a unique variable with four categories:

- "Neutral or positive", whether the respondents' answer was 3), 4) or 5) for both the items a) and $b)$.

- "Negative for me", whether the respondents' answer was 3), 4) or 5) for item a) and 1) or 2) for item $b)$.

- "Negative for me and my family", whether the respondents' answer 1) or 2) for item a) and 3), 4) or 5) for item b)

- "Negative for me and my family", whether the respondents' answer was 1) or 2) for both the items a) and b).

Youth unemployment rate: it is the youth unemployment measured at regional level (NUTS1 or NUTS2 according to the minimum level of aggregation allowed in the Youth Report data. Source: Eurostat) in 2019; it has been added in the econometric model as a macroeconomic control variable with the role of being an alternative to the use of geographical area dummies, as indicator of the presence of a favourable or unfavourable labour market.

A final issue concerning the choice of the model is the question of selectivity, related to the fact that the analysis of the intentions is realized on the sub-sample of those who expressed a positive 
intentions of going to live on their own. Specifying that the aim of this paper is descriptive and exploratory, not causal, a provisional analysis on the distribution of the variables related with the key explanatory variables (employment and education) does not show large differences between the full sample and the subset used in the analysis.

\section{Empirical Results}

This section reports the empirical results and the estimates of parameters $\beta$ in the case parallel lines assumptions are satisfied or less. Three specifications of the model are presented: the first one (Model 1) only includes the socio-demographic variables (gender, age, education, employment status and country of origin), while the second model (Model 2) adds the variable related to the perceived future job/income conditions of the respondents and his family. Finally, a third model (Model 3) has been also introduced, replacing the country dummies with the youth unemployment rates at regional level in 2019. The aim is to explore whether more or less favourable labour market conditions - given the same individual's employment situation -impact on the decision to revise the original plan.

\section{The European sample-Ordered logit}

Table 4 reports the estimates of an ordered logistic regression for the full European sample. Results from Model 1 are partially in line with the expectations: Italy and Spain, net of the other covariates, are the countries that show the highest probability of postponing or abandoning the purpose of leaving the parental home. In this framework, the coefficient for UK is not significantly different from that of Italy and Spain, while people living in Germany and France are more likely to confirm the intention of going to live on their own. Females seem to be more likely to postpone their plans, even if the next models do not confirm the result ${ }^{2}$. With respect to the relationships between the likelihood of revising the plans of residential autonomy and education we notice an inverted U-shaped curve: individuals

\footnotetext{
${ }^{2}$ All the models have been tested separately on women and men. However, because of the small sample size, all the coefficients turn non-significant.
} 
with a tertiary education are less likely to change their plans as well as those with primary or lower secondary education: in this context, those with an upper secondary education seem to be most worried by the emergency. Temporary workers seem to be another penalized category, even if the result is only marginally significant in Model 1 and become irrelevant in Model 2. In Model 2, the perceived future income conditions are precondition for the revision of the intentions to leave the parental home. In particular, those with negative expectations on their personal future income and on both the personal and family's future income experience a higher probability of revising their intentions of leaving the parental home.

Finally, we found that higher level of the regional youth unemployment rate in 2019 predicts higher propensity to abandon or postpone the plan of leaving the parental home (Model 3): the occupational opportunities are important in reducing the perceived risk derived by taking the decision to leave even under the condition of great economic uncertainty.

\section{The Italian sample - Ordered logit}

Table 5 focuses on the Italian sub-sample. Results highlight the relevance of some explanatory variables - such as the employment status and the expectations on the future income - in the Italian context.

In both Model 1 and Model 2, age and gender do not significantly relate with the revision of the autonomy plans. Also the macro-regional context of residence does not matter with respect to the process of revision of the intentions of leaving the parental home. Hence, the significant variables are once again the education, the employment status and, for what concerns Model 2, the income forecasts. About education, results of the Italian subset confirm what has been found in the European sample: individuals with upper secondary education are more likely to abandon or delay their plan of leaving the parental home. Results for the employment status reveal the peculiarity of the Italian 
context compared to the other European countries: the category of temporary workers seems to be the most discouraged in confirming the plan to leave the nest. Also, the category of the students performs worse than the other groups (i.e. permanent workers, self-employed and NEETs). When interpreting the findings for NEETs we need to consider that this subgroup is extremely heterogeneous, as it encompasses both unemployment and inactivity due to many reasons (childcare, taking a "gap year", because they are discouraged, etc.), which are associated with different levels of economic vulnerability (Mascherini and Ledermaier, 2016).

Finally, results for the expected effect of the crisis on the personal and the family future are in line with the ones from the full European sample: a negative expectation on the individual future income induces a downward review of the plans for the Italian young adults. If the negative projections also involve the expected income of the parents, the decision of abandoning or postponing the choice to leave the nest is more likely to happen.

Table 4. Results of ordered logistic regression for the determinants of the decision of postponing or abandoning the plan of going to live on their own: European sample

\begin{tabular}{|c|c|c|c|}
\hline & Model 1 & Model 2 & Model 3 \\
\hline Explanatory variables & Coeff. & Coeff. & Coeff. \\
\hline \multicolumn{4}{|l|}{ Gender } \\
\hline Male & Ref. & Ref. & Ref. \\
\hline Female & $0.183 * *$ & 0.149 & 0.109 \\
\hline \multicolumn{4}{|l|}{ Age } \\
\hline $18-24$ & -0.084 & -0.066 & -0.077 \\
\hline $25-29$ & Ref. & Ref. & Ref. \\
\hline $30-34$ & -0.007 & -0.003 & 0.009 \\
\hline \multicolumn{4}{|l|}{ Education } \\
\hline Tertiary & Ref. & Ref. & Ref. \\
\hline Upper Secondary & $0.211^{* *}$ & $0.214 * *$ & $0.232 * *$ \\
\hline$<$ Upper Secondary & -0.039 & -0.014 & 0.016 \\
\hline \multicolumn{4}{|l|}{ Employment } \\
\hline Neither student nor employed (NEET) & 0.190 & 0.166 & 0.056 \\
\hline Student & 0.073 & 0.071 & 0.009 \\
\hline
\end{tabular}


Self employed

Ref.

Ref.

Ref.

Permanent empoloyee

0.081

0.105

0.073

Temporary worker

$0.280^{*}$

0.269

0.219

\section{Country of residence}

\begin{tabular}{lcc}
\hline Italy & Ref. & Ref. \\
United Kingdom & -0.202 & -0.203 \\
Germany & $-0.708^{* * *}$ & $-0.656^{* * *}$ \\
France & $-0.920 * * *$ & $-0.883^{* * *}$ \\
Spain & -0.115 & -0.107
\end{tabular}

\section{Perceived future job/income conditions}

Positive or neutral for me and my family Ref.

Negative for my family but not for me

$-0.086$

Negative for me only

Negative for me and my family

$0.282 * *$

\begin{tabular}{lccc}
\hline Youth unemployment rate & & $0.017^{* * * *}$ \\
\hline Observations & 1846 & 1846 & 1846 \\
\hline
\end{tabular}

Note: $* * *$ indicates a significance at 0.01 level, $* *$ indicates a significance at 0.05 level, * indicates a significance at 0.10 level

Table 5. Results of ordered logistic regression for the determinants of the decision of postponing or abandoning the plan of going to live on their own: Italian sample

\begin{tabular}{|c|c|c|c|}
\hline & Model 1 & Model 2 & Model 3 \\
\hline Explanatory variables & Coeff. & Coeff. & Coeff. \\
\hline \multicolumn{4}{|l|}{ Gender } \\
\hline Male & Ref. & Ref. & Ref. \\
\hline Female & 0.222 & 0.126 & 0.126 \\
\hline \multicolumn{4}{|l|}{ Age } \\
\hline $18-24$ & 0.181 & 0.219 & 0.228 \\
\hline $25-29$ & Ref. & Ref. & Ref. \\
\hline $30-34$ & -0.053 & -0.089 & -0.087 \\
\hline \multicolumn{4}{|l|}{ Education } \\
\hline Tertiary & Ref. & Ref. & Ref. \\
\hline Upper Secondary & $0.363 * *$ & $0.333 * *$ & $0.330 * *$ \\
\hline$<$ Upper Secondary & 0.100 & 0.090 & 0.100 \\
\hline \multicolumn{4}{|l|}{ Employment } \\
\hline Neither student nor employed (NEET) & 0.362 & 0.319 & 0.322 \\
\hline Student & $0.443 *$ & $0.425 *$ & $0.426^{*}$ \\
\hline
\end{tabular}


Self employed

$$
\text { Ref. }
$$

Ref.

Ref.

Permanent empoloyee

0.283

0.374

0.385

Temporary worker

$0.564 * *$

$0.557 * *$

$0.557 * *$

\section{Macroregion of residence}

\begin{tabular}{lcc}
\hline North West & Ref. & Ref. \\
North East & -0.281 & -0.383 \\
Centre & -0.084 & -0.147 \\
South & -0.056 & -0.097 \\
Islands & 0.085 & 0.026
\end{tabular}

\begin{tabular}{lcc}
\hline Perceived future job/income conditions & & \\
\hline Positive or neutral for me and my family & Ref. & Ref. \\
Negative for my family but not for me & 0.117 & 0.103 \\
Negative for me only & $0.517^{* *}$ & $0.497^{* *}$ \\
Negative for me and my family & $0.645^{* * *}$ & $0.619^{* * *}$ \\
\hline Youth unemployment rate & 0.006 \\
\hline Observations & 733 & 733 \\
\hline Note: *** indicates a significance at 0.01 level, ** indicates a significance at 0.05 level, * indicates a significance at 0.10 level
\end{tabular}

Note: $* * *$ indicates a significance at 0.01 level, $* *$ indicates a significance at 0.05 level, $*$ indicates a significance at 0.10 level

\section{The European sample - Generalized Ordered logit}

As previously said, a Brant test has been implemented with the result of violation of parallel line assumption for several variables. This means that for the variables for which the condition does not hold, we have different values of the estimates of coefficients $\beta$ for each of the cumulative logit models which have replaced the original ordered one; the original ordinal variable is collapsed into two categories and a couple of binary logistic regressions are estimated. The first one contrasts category $j=1$ (confirmation of the plan) with a joint category for levels 2 and 3 (postponement or abandonment). The second one contrasts categories $j=1,2$, which are collapsed in a unique category, against $j=3$.

The analysis starts with the full set of the five European countries in Table 6. Results substantially confirm those we have obtained in Table 4 with few but remarkable differences. With respect to macroeconomic variables, youth unemployment rate confirms to be significant, even if significance 
disappears when country dummies are included in the model ${ }^{3}$. Therefore, the residual variations across countries in the propensity to change the original plans might be better explained by more general contextual characteristics such as the demographic trends (prior to the pandemic), the economic situation, the labour market structures, the house market condition, the welfare support and the cultural context. In particular, young adults from France and Germany are less likely to abandon or to postpone the decision to going living on their own. The model displayed in Table 5 shows an interesting result referring to Spain; differently form the ordered logistic model, the opportunity of relaxing parallel line assumption allows for discussing a more articulated pattern or preferences. Spanish young adults are not significantly different from Italian ones when we compare the decision of confirming the purpose of leaving home with the alternative of delaying or abandoning the plan. However, when we split the alternative of abandoning from that of delaying and we contrast abandoning vs. delay/confirmation the results changes, showing Spaniards being less likely to abandon their purpose and generally more optimistic than Italians.

A more complex pattern of preferences concerns the variable on perceived future income conditions. When we control for youth unemployment rate, a negative perspective on the future of both individual and household income reinforce the choice of abandoning the purpose of leaving away with respect to the choice of simply delaying that choice.

Finally, generalized logit provides an interesting pattern of results for the role of education and specifically for the group of lower educated individuals. While individuals with a secondary education keep showing a higher probability of delaying or abandoning the intentions of departing, lower educated individuals are less likely to opt for a delay compared to higher educated ones. In the model contrasting the choice of confirming to postponing/abandoning the coefficient is negative, indicating that lower educated young adults are more likely to confirm. When we contrast the choice of confirming or delaying the intentions versus the most radical choice of abandoning the plan, the

\footnotetext{
${ }^{3}$ This finding is obtained implementing a regression analysis with the joint presence of geographical area dummies and youth unemployment rate. The details of that model are omitted in Table 6.
} 
coefficient changes the sign and become positive, indicating a preference for renouncing to the purpose of exiting from the parental home. In both the cases, the lower educated individuals seem to polarize their preferences toward the two opposite alternatives: leaving the parental home even in presence of Covid-19 emergency or totally renounce to the plan.

\section{The Italian sample - Generalized Ordered logit}

The Italian sample reflects the result from the European countries with some peculiarities, confirming the results from the Ordered Logit. Students and temporary workers are more likely to delay or abandon the plan of leaving the parental home. The situation appears critical especially for those who have fixed term jobs, a condition which often becomes chronical in Italy and which is the basis of the delay of several events in Italians' life course path. Hence, the presence of a precarious employment condition seems to be the main predictor for risk of postponement or of the abandonment of the purpose of joining the residential autonomy. In this context, being precarious increases the risk of revising the life plan even more than for the group of NEETs. Anyway, as already discussed, the category of NEET is extremely heterogeneous, which makes difficult to find a general explanation for the lower propensity to revise their plans.

In this framework, it is important to underline as regional context does not matter when we consider the scenario of Covid-19 pandemic in Italy. Indeed, both the regional dummies and the youth regional unemployment rate are not significant. Probably, the higher incidence of cases in Lombardy, Veneto and Emilia Romagna, which are among the wealthier regions, have decreased the expectations also here, by flattening the regional gap.

Generalized logit estimates are particularly interesting for what concerning the role of gender and education. Unlike what was found in the European sample, in Italy gender differences matter, with females that are more likely to abandon the choice of leaving home in the model contrasting levels of $j=1,2$ (confirmation/delay) vs. $j=3$ (abandonment). This means that females declare to be less optimistic with the perspective of going to live on their own. Upper secondary educated individuals 
are more likely to abandon their leaving plan only in the model where those postponing and still planning are jointly considered against those who totally abandoned their plan.

Finally, as in the European subset, a negative perception of the future income for the respondents and their family increase the likelihood of abandoning the plan instead of confirming or delaying it. Therefore, the negative effects of future income and of a temporary employment status emphasize the key role of expectations, more than the actual conditions, in modifying the individuals' plans. 
Table 6. Results of generalized ordered logistic regression for the determinants of the decision of postponing or abandoning the plan of going to live on their own: European sample

Model 1

Model 2

Model 3

Coeff. 3, 2 Coeff. 3, Coeff. 3, 2 Coeff. 3, Coeff. 3, 2 Coeff. 3,

$\begin{array}{lllllll}\text { Explanatory variables } & \text { vs. } 1 & \text { vs. } 1,2 & \text { vs. } 1 & \text { vs. } 1,2 & \text { vs. } 1 & \text { vs. } 1,2\end{array}$

\begin{tabular}{llllllc}
\hline \hline Gender & & & & & & \\
Male & Ref. & Ref. & Ref. & Ref. & Ref. & Ref. \\
Female & 0.032 & 0.032 & 0.148 & 0.148 & 0.106 & 0.106 \\
\hline Age & & & & & & \\
\hline $18-24$ & -0.083 & -0.083 & -0.074 & -0.074 & -0.082 & -0.082 \\
$25-29$ & Ref. & Ref. & Ref. & Ref. & Ref. & Ref. \\
$30-34$ & -0.002 & -0.002 & -0.001 & -0.001 & 0.009 & 0.009 \\
\hline
\end{tabular}

\section{Education}

\begin{tabular}{lcccccc}
\hline Tertiary & Ref. & Ref. & Ref. & Ref. & Ref. & Ref. \\
Upper Secondary & $0.217^{* *}$ & $0.217^{* *}$ & $0.223^{* *}$ & $0.223^{* *}$ & $0.242^{* *}$ & $0.242^{* *}$ \\
$<$ Upper Secondary & -0.286 & 0.252 & $-0.302^{*}$ & $0.310^{*}$ & $-0.336^{* *}$ & $0.400^{* *}$ \\
\hline Employment & & & & & & \\
\hline Neither student nor employed (NEET) & 0.171 & 0.171 & 0.152 & 0.152 & 0.049 & 0.049 \\
Student & -0.127 & 0.243 & -0.127 & 0.243 & -0.166 & 0.165 \\
Self employed & Ref. & Ref. & Ref. & Ref. & Ref. & Ref. \\
Permanent empoloyee & 0.059 & 0.059 & 0.085 & 0.085 & 0.065 & 0.065 \\
Temporary worker & 0265 & 0.265 & 0.261 & 0.261 & 0.223 & 0.223 \\
\hline
\end{tabular}

\section{Country of residence}

\begin{tabular}{lcccc}
\hline Italy & Ref. & Ref. & Ref. & Ref. \\
United Kingdom & -0.170 & -0.170 & -0.164 & -0.164 \\
Germany & $-0.635^{* * *}$ & $-0.635^{* * *}$ & $-0.589^{* * *}$ & $-0.589 * *$ \\
France & $-0.598^{* * * *}$ & $-1.453^{* * *}$ & $-1.376^{* * *}$ & $-1.376^{* * *}$ \\
Spain & 0.226 & $-0.341^{* *}$ & -0.320 & $-0.320^{* *}$
\end{tabular}

\section{Perceived future job/income conditions}

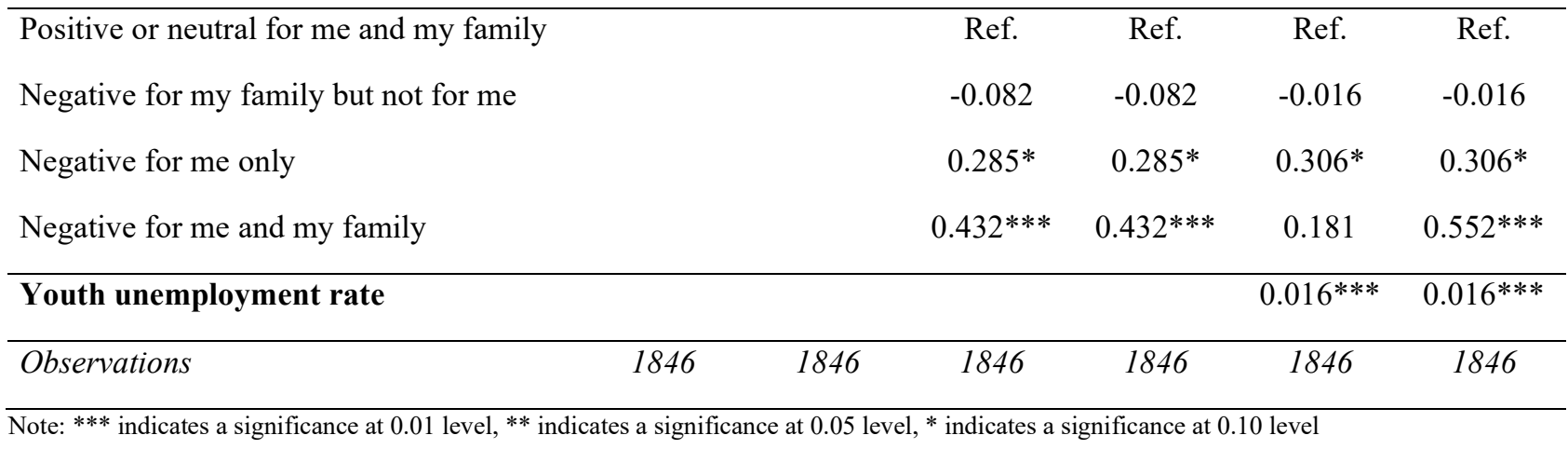


Table 7. Results of generalized ordered logistic regression for the determinants of the decision of postponing or abandoning the plan of going to live on their own: European sample

\begin{tabular}{|c|c|c|c|c|c|c|}
\hline \multirow[b]{2}{*}{ Explanatory variables } & \multicolumn{2}{|c|}{ Model 1} & \multicolumn{2}{|c|}{ Model 2} & \multicolumn{2}{|c|}{ Model 3} \\
\hline & Coeff. & Coeff. & Coeff. & Coeff. & Coeff. & Coeff. \\
\hline \multicolumn{7}{|l|}{ Gender } \\
\hline Male & Ref. & Ref. & Ref. & Ref. & Ref. & Ref. \\
\hline Female & -0.154 & $0.423 * * *$ & -0.199 & $0.300 *$ & -0.202 & $0.301 *$ \\
\hline \multicolumn{7}{|l|}{ Age } \\
\hline $18-24$ & 0.168 & 0.168 & 0.191 & 0.191 & 0.200 & 0.200 \\
\hline $25-29$ & Ref. & Ref. & Ref. & Ref. & Ref. & Ref. \\
\hline $30-34$ & -0.060 & -0.060 & -0.100 & -0.100 & -0.101 & -0.101 \\
\hline \multicolumn{7}{|l|}{ Education } \\
\hline Tertiary & Ref. & Ref. & Ref. & Ref. & Ref. & Ref. \\
\hline Upper Secondary & 0.060 & $0.590 * * *$ & 0.006 & $0.558 * * *$ & 0.007 & $0.555 * * *$ \\
\hline$<$ Upper Secondary & -.337 & 0.419 & -0.341 & 0.415 & -0.326 & 0.425 \\
\hline \multicolumn{7}{|l|}{ Employment } \\
\hline Neither student nor employed (NEET) & 0.342 & 0.342 & 0.298 & 0.298 & 0.300 & 0.300 \\
\hline Student & $0.439 *$ & $0.439 *$ & $0.428 *$ & $0.428^{*}$ & $0.429 *$ & $0.429 *$ \\
\hline Self employed & Ref. & Ref. & Ref. & Ref. & Ref. & Ref. \\
\hline Permanent empoloyee & 0.255 & 0.255 & 0.342 & 0.342 & 0.353 & 0.352 \\
\hline Temporary worker & $0.558 * *$ & $0.558 * *$ & $0.554 * *$ & $0.554 * *$ & $0.553 * *$ & $0.553 * *$ \\
\hline \multicolumn{7}{|l|}{ Macroregion of residence } \\
\hline North West & Ref. & Ref. & Ref. & Ref. & & \\
\hline North East & -0.269 & -0.269 & -0.369 & -0.369 & & \\
\hline Centre & -0.102 & -0.102 & -0.165 & -0.165 & & \\
\hline South & -0.070 & -0.070 & -0.109 & -0.109 & & \\
\hline Islands & 0.070 & 0.070 & 0.016 & 0.016 & & \\
\hline
\end{tabular}

\section{Perceived future job/income conditions}

\begin{tabular}{lcccc}
\hline Positive or neutral for me and my family & Ref. & Ref. & Ref. & Ref. \\
Negative for my family but not for me & 0.132 & 0.132 & 0.119 & 0.119 \\
Negative for me only & $0.558^{* *}$ & $0.558^{* *}$ & $0.537^{* *}$ & $0.537^{* *}$ \\
Negative for me and my family & $0.351^{*}$ & $0.812^{* * *}$ & 0.326 & $0.786^{* * *}$ \\
\hline Youth unemployment rate & & & 0.005 & 0.005 \\
\hline Observations & 733 & 733 & 733 & 733 \\
\hline Note: *** indicates a significance at 0.01 level, ** indicates a significance at 0.05 level, * indicates a significance at 0.10 level
\end{tabular}




\section{Conclusions}

This study offers an explorative analysis of the possible effect of the Covid-19 pandemic on the young population projects of leaving the parental home. As far as we know, this is the first study on the topic conducted on international representative samples of the young population (18-34) of five European countries $^{4}$. Results from our paper suggest that precarious employment situation and bad perspective financial conditions of the young individuals and their families are associated with a negative revision of their intention of leaving the parental home because of the Covid-19 related economic crisis. This path is particularly stressed in the Italian case. Here, having a temporary job and feeling insecure about the future financial situation are strong predictors of a downward revision of the original plan about reaching housing autonomy. These results seem to confirm the idea that both the objective conditions of the present and the perception of uncertainty about the future count on the life plans of young people.

In particular, the vulnerability of temporary workers needs to be taken into serious consideration by policy makers, especially because this condition is dominant for those entering in the labour market (Standing, 2011; Ashton, 2017; Bloodworth, 2018). Fixed-term, temporary and zero-hour contracts are particularly common among the youngest, 16 to 24 year-olds (Eurostat, 2017), and in countries such as Spain, Italy and Germany. However, while in Germany temporary contracts are often transitory to permanent contracts, in Italy and Spain temporary contracts are involuntary in most of the cases and less frequently end up into permanent jobs (Mascherini et al. 2013). A standing-alone case is the UK, where temporary contracts are much rarer than in other European countries, and in one third of the cases even by worker's choice (Schoon and Bynner 2019). This mirror the liberal

\footnotetext{
4 From data on the same survey see: https://blogs.lse.ac.uk/europpblog/2020/06/16/there-is-noevidence-of-a-covid-19-baby-boom-in-europe-but-there-is-of-a-bust/
} 
soul of the UK economy and the higher level of de-regularization of the labour market, where dismissing is much easier than elsewhere.

Across countries, the propensity to revise the original plan of attaining a residential autonomy remains higher in Italy, Spain and UK, even controlling for the occupational condition and the expected effect of the crisis on the individual's and family's income. As argued, the institutional framework plays a primary role in shaping the opportunities and the resources that young people can access to support their transition towards the autonomy from the family of origin. The uncertainty brought by the Covid-19 health and economic crisis can only magnify the contextual effect on this process. Therefore, familialistic as liberal welfare regimes do not offer enough financial guarantees to reduce the increased risk of leaving the nest during period of great (global) uncertainty. At the same time, previous unfavourable conditions of both the economic system and the labour market do not provide young people with a solid ground on which they can build their own house. Even though we still do not have evidence on how the current pandemic and economic crisis will affect future concrete behaviours, results from our study confirm the negative impact of the current recession at least on the intentions of the young generations to pursue their life plans. Further studies are then needed to estimate the impact of the current crisis on the actual realization of young generations life plans in the next future. Still, our first empirical evidence suggests urgent policy interventions to support young people in getting their economic and housing independence, especially in those countries where the transition to adulthood was already an issue before the pandemic occurred. 


\section{References}

Aassve, A., Billari, F. C., Mazzuco, S., \& Ongaro, F. (2002). Leaving home: A comparative analysis of ECHP data. Journal of European social policy, 12(4), 259-275.

Aassve, A., Iacovou, M., \& Mencarini, L. (2006). Youth poverty and transition to adulthood in Europe. Demographic Research, 15(2), 21-50. doi:10.4054/DemRes.2006.15.2.

Aassve, A., Davia, M.A., Iacovu, M. \& Mazzucco, S. (2007). Does Leaving Home Make You Poor? Evidence from 13 European countries. European Journal of Population, 23, 315-338.

Aassve, A., \& Lappegård, T. (2009). Childcare cash benefits and fertility timing in Norway. European Journal of Population. 25(1), 67-88. doi:10.1007/s10680-008-9158-6.

Aassve, A., Arpino, B., \& Billari, F. C. (2013). Age norms on leaving home: Multilevel evidence from the European Social Survey. Environment and Planning A. 45(2), 383-401.

Ashton, D. (2017) Globalization and its impact on the political, economic, and labor market aspects of the youth transition. In I. Schoon and J. Bynner (eds) Young people's development and the Great Recession: Uncertain transitions and precarious futures ( $\mathrm{pp}$ 25-5) Cambridge: Cambridge University Press. doi: 10.1017/9781316779507.003

Barbieri, P. (2011). Italy: no country for young men (and women). In Buchholz S., Hofaecker D. (eds.), The Flexibilization of European Labor Markets: The Development of Social Inequalities in an Era of Globalization (pp. 108-145), Cheltenham, UK/Northampton, MA: Edward Elgar.

Bell, L., Burtless, G., Gornick, J., \& Smeeding, T. M. (2007). Failure to launch: Cross-national trends in the transition of economic independence. In S. Danziger \& C. E. Rouse (Eds.), The price of independence: The economics of early adulthood (pp. 27-55). New York: Russell Sage Press

Bell, D.N.F. \& Blanchflower, D.G. (2011) Young people and the Great Recession. Oxford Review of Economic Policy, 27(2): 241-67. 
Billari, F. (2004). Becoming an adult in Europe: A macro (/micro)- demographic perspective. Demographic Research, 3, 15-44. doi:10.4054/DemRes.2004.S3.2.

Billari, F.C., D. Philipov, \& P. Baizán (2001). Leaving Home in Europe. The Experience of Cohorts Born Around 1960. International Journal of Population Geography, 7, 339-56.

Billari, F. C., \& Liefbroer, A. C. (2007). Should I stay or should I go? The impact of age norms on leaving home. Demography, 44(1), 181-198.

Blanchflower, D. G., \& Freeman, R. B. (2000). The declining economic status of young workers in OECD countries. In Youth employment and joblessness in advanced countries (pp. 19-56). Chicago: University of Chicago Press

Bloodworth, J. (2018) Hired: Six months undercover in low-wage. Britain, London: Atlantic Books.

Blossfeld, H. P., Klijzing, E., Mills, M., \& Kurz, K. (2005). Globalisation, uncertainty, and youth in society. London: Routledge.

Brant, R. (1990). Assessing proportionality in the proportional odds model for ordinal logistic regression. Biometrics, 46, 1171-1178. doi:10.2307/2532457

Breen, R. (2005). Explaining cross-national variation in youth unemployment: Market and institutional factors. European Sociological Review, 21(2), 125-134. doi:10.1093/esr/jci008.

Brzinsky-Fay, C. (2007). Lost in transition? Labour market entry sequences of school leavers in Europe. European Sociological Review, 23(4), 409-422. doi:10.1093/esr/jcm011.

Buchmann, M. C., \& Kriesi, I. (2011). Transition to adulthood in Europe. Annual Review of Sociology, 37, 481-503. doi:10.1146/ annurev-soc-081309-150212

Cho, Y. and Newhouse, D. (2013). How Did the Great Recession Affect Different Types of Workers? Evidence from 17 Middle-Income Countries. World Development 41(0): 31-50. doi:10.1016/j.worlddev.2012.06.003. 
Dalla Zuanna G. (2001). The banquet of Aeolus: A familistic interpretation of Italy's lowest low fertility. Demographic Research, 4, 133-162.

Dalla Zuanna G. \& Micheli G.A. (2004). Strong family and low fertility: a paradox? New perspective in interpreting contemporary family and reproductive behavior. Dordrecht, Kluwer Academic Publishers.

De Jong Gierveld, J., A.C. Liefbroer, E. \& Beekink (1991). The Effect of Parental Resources on Patterns of Leaving Home Among Young Adults in the Netherlands. European Sociological Review $7: 55-71$.

Esping-Andersen, G. (1990). The three worlds of welfare capitalism. Princeton University Press.

Furstenberg, F. F. Jr. (2010). On a new schedule: Transitions to adulthood and family change. The Future of Children, 20(1), 67-87

Gangl, M. (2002). Changing labour markets and early career outcomes: Labour market entry in Europe over the past decade. Work, Employment and Society, 16(1), 67-90. doi:10.1177/09500170222119254.

Goldscheider, F.K. \& C. Goldscheider (1989). Family Structure and Con ict: Nest-Leaving Expectations of Young Adults and Their Parents. Journal of Marriage and the Family 51:87-97.

Goldscheider, F.K. \& C. Goldscheider (1993). Leaving Home Before Marriage. Ethnicity, Familism and Generational Relationships. Madison, WI: University of Wisconsin Press

Grusky, D. B., Western, B., \& Wimer, C. C. (2011). The great recession. New York: Russell Sage Foundation.

Iacovu M. (2010). Leaving Home: Independence, togetherness and income in Europe. Advances in Life Course Events, 15(4): 147-160. 
Hout, M., Levanon, A., \& Cumberworth, E. (2011). Job loss and unemployment. In D. B. Grusky, B. Western \& C. C. Wimer (Eds.), The great recession (pp. 59-81). New York: Russell Sage Foundation Lesthaeghe, R., \& Van de Kaa, D. J. (1986). Two demographic transitions. Population growth and decline, 9-24.

Lin C.Y., Edvinsson L., Chen J. \& Beding T. (2013). National Intellectual Capital and the Financial Crisis in Greece, Italy, Portugal, and Spain. Springer Briefs in Economics, Springer, Heidelberg.

Marcus, R., \& Gavrilovic, M. (2010). The impacts of the economic crisis on youth: Review of evidence. London: Overseas Development Institute.

Mascherini, M., Ledermaier, S., Vacas-Soriano, C., \& Jacobs, L. (2017). Long-term unemployed youth: Characteristics and policy responses. Luxembourg: Publications Office of the European Union.

Mascherini, M., \& Ledermaier, S. (2016). Exploring the diversity of NEETs. Luxembourg: Publications Office of the European Union.

Mayer, K. U. (2001). The paradox of global social change and national path-dependencies: Life course patterns in advanced societies. In A. Woodward \& M. Kohli (Eds.), Inclusions and exclusions in European societies (pp. 89-110). London: Routledge.

Mills, M., \& Blossfeld, H. P. (2003). Globalization, uncertainty and changes in early life courses. Zeitschrift für Erziehungswissenschaft, 6(2), 188-218.

Mills, M., Blossfeld, H. P., Buchholz, S., Hofäcker, D., Bernardi, F., \& Hofmeister, H. (2008). Converging divergences? An international comparison of the impact of globalization on industrial relations and employment careers. International Sociology, 23(4), 561-595. doi: $10.1177 / 0268580908090728$ 
Mínguez, A. M. (2017). Understanding the impact of economic crisis on inequality, household structure, and family support in Spain from a comparative perspective. Journal of Poverty, 21(5), 454-481.

Mulder, C. H., Clark, W. A., \& Wagner, M. (2002). A comparative analysis of leaving home in the United States, the Netherlands and West Germany. Demographic Research, 17, 567-592. doi:10.4054/DemRes.2007.17.19.

O’Higgins, N. (2014). Institutions and youth labour markets in Europe during the crisis. In P. Tridico \& L. Mamica (Eds.), Economic policy and the financial crisis (pp. 90-114). Abingdon: Routledge.

Rosina A., Micheli GA., \& Mazzucco S. (2007). An Analysis of Young People's Risk of Difficulties on Leaving the Parental Home. Italian Journal of Social Policy 4(3): 95-111

Santarelli E., \& Cottone F. (2009). Leaving Home, Family Support and Intergenerational Ties in Italy: Some Regional Differences. Demographic Research, 21, 1-22.

Scherer, S. (2005). Patterns of labour market entry-long wait or career instability? An empirical comparison of Italy, Great Britain and West Germany. European Sociological Review, 21(5), 427440. doi:10.1093/esr/jci029.

Schoon, I. \& Bynner, J. (eds) (2017). Young people's development and the Great Recession: Uncertain transitions and precarious futures, Cambridge: Cambridge University Press

Schoon, I., \& Bynner, J. (2019). Young people and the Great Recession: Variations in the school-towork transition in Europe and the United States. Longitudinal and Life Course Studies, 10(2), 153173.

Settersten, R. A. Jr., Furstenberg, F. F., \& Rumbaut, R. G. (2008). On the frontier of adulthood: Theory, research, and public policy. Chicago: University of Chicago Press 
Sironi, M. (2015). Transition to adulthood. In J. D. Wright (Ed.), International encyclopedia of the social \& behavioral sciences (pp. 571-575). Amsterdam: Elsevier

Sironi, M. (2018). Economic conditions of young adults before and after the Great Recession. Journal of family and economic issues, 39(1), 103-116.

Sironi, M., \& Furstenberg, F. F. (2012). Trends in the economic independence of young adults in the United States: 1973-2007. Population and Development Review, 38(4), 609-630.

Sironi, E., \& Rosina, A. (2016). Leaving the parental home in Italy during the economic crisis. Genus, 71(2-3).

Standing, G. (2011). The precariat: The new dangerous class. London: Bloomsbury

Surkyn, J. \& R. Lesthaeghe (2004). Value Orientations and the Second Demographic Transition (SDT) in Northern, Western and Southern Europe: An Update. Demographic Research, Special Collection 3: Article 3. Available online at http://www.demographic-research.org/special/3/3/ default.htm

Trifiletti, R. (1999). Southern European welfare regimes and the worsening position of women. Journal of European social policy, 9(1), 49-64. doi:10.1177/095892879900900103.

Verick, S. (2009). Who is hardest hit during a financial crisis? The vulnerability of young men and women to unemployment in an economic downturn. In IZA discussion Paper, no. 4359. Bonn: Institute for the Study of Labor.

Vignoli, D., Drefahl, S., \& De Santis, G. (2012). Whose job instability affects the likelihood of becoming a parent in Italy? A tale of two partners. Demographic Research, 26, 41-62.

Vignoli, D., Rinesi, F., \& Mussino, E. (2013). A home to plan the first child? Fertility intentions and housing conditions in Italy. Population, Space and Place, 19(1), 60-71. 
Vignoli, D., Tocchioni, V., \& Salvini, S. (2016). Uncertain lives: Insights into the role of job precariousness in union formation in Italy. Demographic Research, 35, 253-282.

Williams, R. (2016). Understanding and interpreting generalized ordered logit models. The Journal of Mathematical Sociology, 40(1), 7-20. doi.org/10.1080/0022250X.2015.1112384 